\title{
Journal of Critical Care \& Emergency Medicine
} Dislocation Without Fracture in Lumbar Spine and Delayed Ileal Perforation

\author{
İlyas Kar1 ${ }^{1}$ Engin Kesgin ${ }^{2}$, Çağdaş Deniz Gündüz ${ }^{3}$, Mürsel Koçer ${ }^{4}$ and Bekir Yavuz Uçar ${ }^{*}$ \\ ${ }^{1}$ Orthopaedics and Traumatology, University of Health Sciences Umraniye Education and Research Hospital, İstanbul \\ ${ }^{2}$ Orthopaedics and Traumatology, Antalya Atatürk Public Hospital, Antalya \\ ${ }^{3}$ Orthopaedics and Traumatology, Birecik Public Hospital, Şanlıurfa
}

${ }^{4}$ Emergency Medicine, Birecik Public Hospital, Şanlıurfa

${ }^{5}$ Orthopaedics and Traumatology \& Spine Surgery, University of Health Sciences Umraniye Education and Research Hospital, İstanbul

\begin{abstract}
Introduction: The seat belt syndrome is a term used for multiple injuries associated with seat belt use during a traffic accident. Among these injuries, attention should be paid to spine and abdominal traumas that could be fatal.

Case Presentation: This case report describes a 34-year-old woman wearing only a lap belt removing the upper part of her seat belt to breastfeed her baby in the back seat of the car during a traffic accident. Bilateral facet dislocation in lumbar spine without fracture and delayed ileal perforation were found. Spine surgery was performed urgently. Abdominal injury was detected 24 hours after spine surgery.

Discussion: This case demonstrates the importance of the seat belt syndrome. It also supports why this type of injured patient needs close follow-up. Various rare injuries may be encountered. The trauma team must be alert in seat belt related traffic accidents, where many different injuries can be seen.
\end{abstract}

\section{${ }^{\star}$ Corresponding author}

Bekir Yavuz Uçar, University of Health Sciences Umraniye Education and Research Hospital, İstanbul;E-mail: bekiryavuzucar@gmail.com

Received: February 24, 2022; Accepted: March 03, 2022; Published: March 08, 2022

\section{Introduction}

The Seat belt syndrome is a term that is used for multiple injuries associated with the use of seat belts. These injuries are explained by the transmission of physical force. The seat belt can act as a fulcrum, with a point of contact remaining fixed in the same location, while the areas above and below continuing forward. This paper is a traffic accident case report of a 34-year-old woman wearing only the lap belt removing the upper part of her seat belt to breastfeed a child in the back seat in the car. We will present two noteworthy points. One of them is bilateral facet dilocation without fracture, a rare injury of the lumbar spine. The other is delayed intestinal injury. The case we presented is the first in the literature to be a case of seat belt syndrome with bilateral facet dislocation in lumbar spine without fracture.

\section{Case Presentation}

A 34 years old female was presented to emergency after sustaining road traffic accident. She was a passenger in the back seat on the right. She took off the upper part of her seat belt and was breastfeeding her baby. Meanwhile, they had a casualty accident. On presentation, she was conscious, breathing spontaneously, vitally stable. While there was mild tenderness in the abdominal examination, there was severe sensitivity in the lumbar area in the spinal examination. She was neurologically intact. There was no pathologies in extremities. Computed tomography (CT) abdomen showed no significant abdominal or pelvic findings [figure 1]. L3-L4 bilateral facet dislocation without fracture and instability was found in the CT and MRI spine [figure 2].

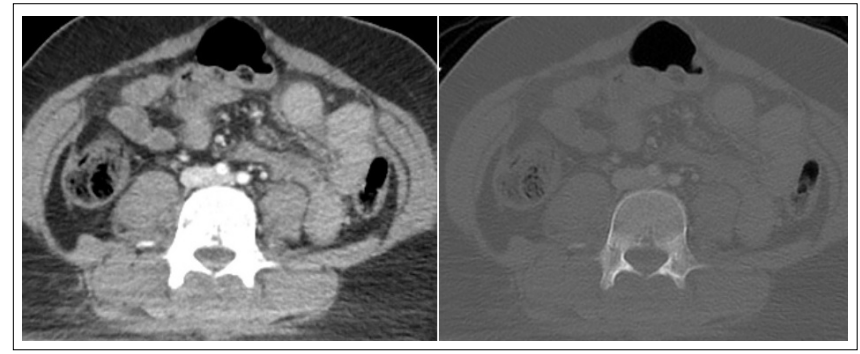

Figure 1 

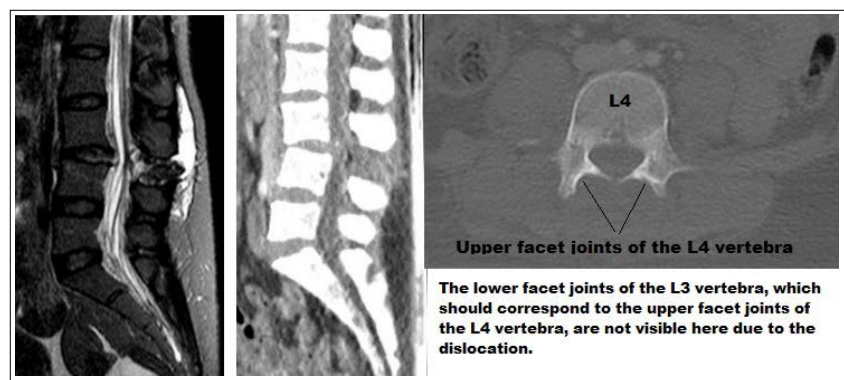

Figure 2

The patient was taken to emergency surgery. During the operation, severe instability at the L3-L4 level was observed. spinous ligaments and bilateral ligamentum flavums were torn. There was a hematoma in that area. Stabilization was completed with posterior instrumentation between L2 and L5 [figure 3]. She was mobilized at the 4th hour postoperatively. She could walk without support. She started to complain of abdominal pain at the 24th hour of the operation. Abdominal pain was getting worse during mobilization. Abdominal CT was taken to the patient. CT abdomen showed mesenteric stranding fluid collection and ileum thickening [figure 4]. She was posted of exploratory laparotomy which revealed perforation in the ileum. In exploration, approximately $300 \mathrm{cc}$ of gastrointestinal content and a perforation area $40 \mathrm{~cm}$ proximal to the ileocecal valve were observed in the right paracolic area. The inside of the abdomen was cleaned abundantly with salin solutions. Segmental resection and anastomosis was performed. The postoperative course in regard to enteral feeding and mobilization was unremarkable. No wound pathologies were seen in both surgical areas [figure 5]. The drain was removed on a timely manner as planned. The wound underwent proper primary healing and sutures removed on time for both surgical areas.
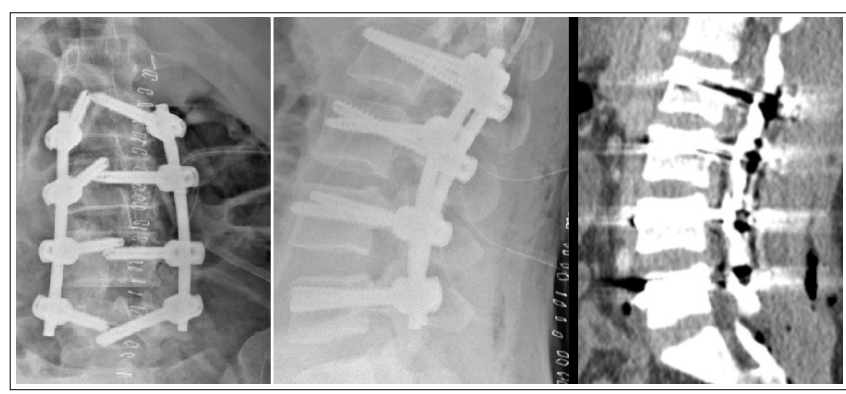

Figure 3

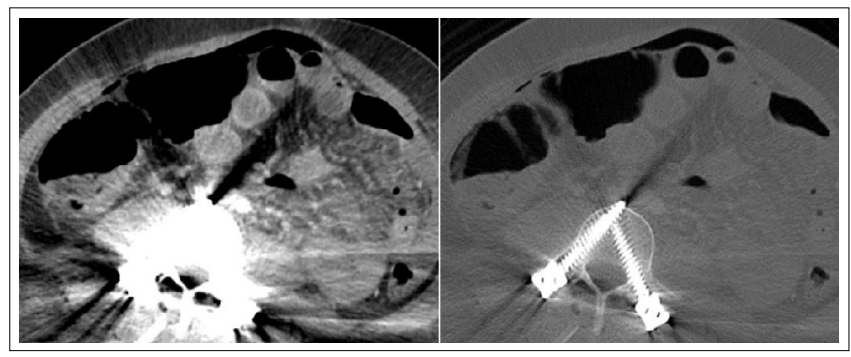

Figure 4

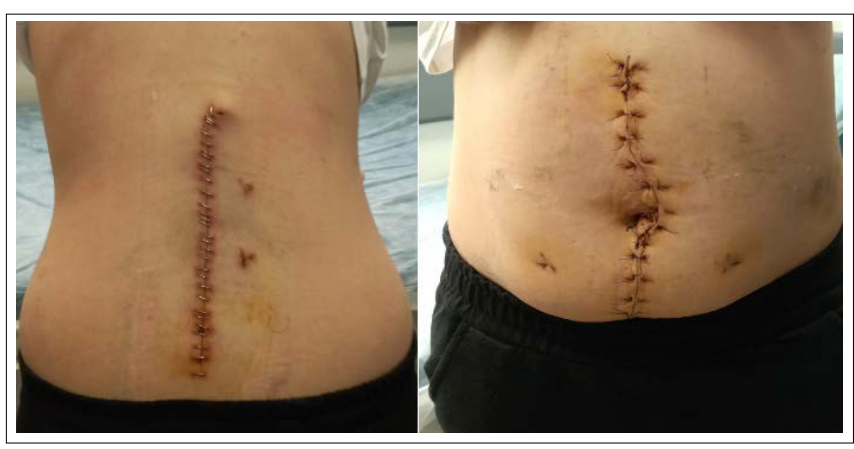

Figure 5

There was no complaint in the first year follow-up. Our patient, who is an engineer, continues her work and life where she left off. First year control X-rays are seen in figure 6.

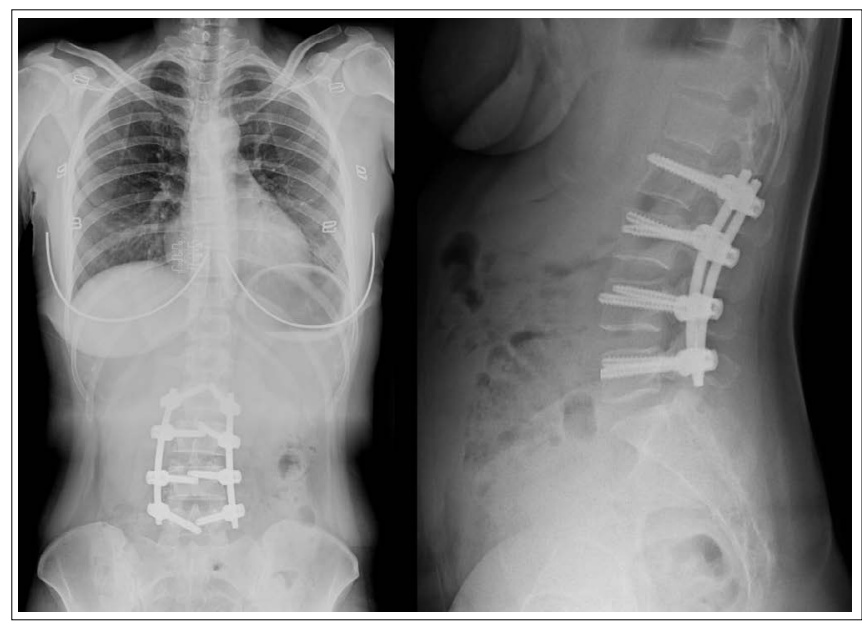

Figure 6

\section{Discussion}

The seat belt syndrome which was first reported in 1962 by Garnett and Braunstein was defined for multiple injuries occurring in the contact areas of the seat belt after sudden flexion distraction force during an accident [1]. The seat belt syndrome is characteristically involves seat belt sign in association with intestinal perforation or mesenteric tear and lumbar spine fracture or dislocation [1,2]. In first report of seat belt syndrome the authors, in their analysis of 944 injuries sustained by persons wearing lap seat belt, reported only 12 with lumbar spine injuries [1]. Mostly injuries were abdominal organs.

In 1969, Steckler et al. drew attention to the seat belt trauma to the lumbar spine in seat belt syndrome [2]. They used the title "an unusual manifestation of the seat belt syndrome" to their paper. In this paper they reported a case that was severe trauma to the lumbar spine and cauda equina.

After these two first publications, many case reports and reviews presented to the literature [3-5]. The cases of child seat belt injuries were also presented [6].

The seat belt syndrome is most commonly associated with using a lap belt but also has been reported in occupants using three-point restraints $[3,4]$.

Isolated facet dislocation rarely seen in lumbar region, is a very unstable injury. These are the result of high-energy trauma and 
are associated with high incidence of neurological damage. Medagam et al. reported their paraplegia case of pure bilateral facet dislocation of the L1 - L2 vertebra [5]. We determined L3 L4 isolated bilateral facet dislocation without neurological deficit in our case which is a seat belt injury accompanied by intestinal injury. It is the first bilateral facet dislocation without fracture of the lumbar spine presented as a seat belt syndrome in the literature. Injury of the lumbar spine is seen with lap belts because of hyperflexion jackknifing of the upper and lower portions of the body against the seat belt.

Bruising of the anterior abdominal wall known as the 'seat belt sign' is a warning sign for intestinal injury [7]. However caution also should be exercised in cases where seat belt sign is not seen [8]. In our case, there was no seat belt sign.

Clinical signs of intestinal injuries might not be obvious on presentation. There are case reports about the delayed diagnosis of intestinal injuries of seat belt syndrome in the literature $[9,10]$. In the presence of seat belt-related traffic accident the possibility of intestinal injury must be suspected. The patient should be kept under close observation even if no clinical or radiological findings are present at presentation.

We also found delayed intestinal injury in accordance with the literature in our case. There was no significant abdominal pathologies clinically and radiologically on presentation. We focused on the spinal dislocation and urgently underwent spine surgery. After 24 hours, intestinal injury was diagnosed with CT taken due to abdominal pain.

\section{Conclusion}

Early diagnosis of seat belt injuries is vital. It is very important to be alert for intestinal injuries that cannot be diagnosed in the early hours of the trauma. The trauma team must be alert in seat belt related traffic accidents, where many different injuries can be seen. Orthoapedic surgeons, spine surgeons, abdominal surgeons and thoracic surgeons should work in coordination and have a good command of the case.

Mostly spine surgeons are the first to intervene and perform the surgery, because the spinal injury is noticed earlier. Spine surgeons should be alert to delayed abdominal injuries while intervening in such seat belt traumas and should be in close contact with abdominal surgeons during follow-up.

\section{References}

1. Garrett JW, Braunstein PW (1962)The seat belt syndrome. J Trauma 2: 220-238.

2. Steckler RM, Epstein JA, Epstein BS(1969) Seat belt trauma to the lumbar spine: an unusual manifestation of the seat belt syndrome. J Trauma 9: 508-513.

3. Torba M, Hijazi S, Gjata A, Buci S, Madani R etal. (2014) Seat belt syndrome, a new pattern of injury in developing countries. Case report and review of literature. G Chir 35:17780.

4. Gill SS, Dierking JM, Nguyen KT, Woollen CD, Morrow CE (2004) Seatbelt injury causing perforation of the cervical esophagus: a case report and review of the literature. Am Surg 70: 32-34.

5. Medagam NR, Dhillon CS, Dwivedi R, Jindal PK, Ega S (2018) Rare Case of Bilateral Pure Facet Joint Dislocation of Upper Lumbar Spine without Facet Fracture: A Case Report. J Orthop Case Rep 2018 8:58-60.
6. Szadkowski MA, Bolte RG (2017) Seatbelt Syndrome in Children. Pediatr Emerg Care 33:120-125.

7. Jiang O, Asha SE, Keady J, Curtis K (2019) Position of the abdominal seat belt sign and its predictive utility for abdominal trauma. Emerg Med Australas 31: 112-116.

8. Özçay N, Brosova I, Ferkodic M, Özant A, Arslan K etal. (2018) Two cases of intestinal injuries due to seat belt without seat belt sign. J Surg Case Rep 13: 298.

9. Al-Ozaibi L, Adnan J, Hassan B, Al-Mazroui A, Al-Badri F (2016) Seat belt syndrome: Delayed or missed intestinal injuries, a case report and review of literature. Int J Surg Case Rep 20: 74-76.

10. Enderson BL, Maull KI (1991) Missed injuries. The trauma surgeon's nemesis. Surg Clin North Am 71: 399-418.
Copyright: (C2022 Bekir Yavuz Uçar, et al. This is an open-access article distributed under the terms of the Creative Commons Attribution License, which permits unrestricted use, distribution, and reproduction in any medium, provided the original author and source are credited. 